\title{
Organic geochemical evaluation of contamination tracers in deepwater well rock cuttings from the Mannar Basin, Sri Lanka
}

\author{
Amila Sandaruwan Ratnayake ${ }^{1,2} \cdot$ Yoshikazu Sampei $^{1}$
}

Received: 27 November 2017 / Accepted: 2 November 2018 / Published online: 15 November 2018

(c) The Author(s) 2018

\begin{abstract}
Geochemical data from rock-cutting samples can give rise to faulty interpretations due to contamination from drilling fluids used in modern deepwater petroleum exploration. In this study, oil-based drilling contaminants were removed by solvent extraction with dichloromethane and methanol (9:1) solution. Bulk and molecular organic geochemical characteristics were examined for both oil-based drilling mud and cleaned rock-cutting samples. Total organic carbon (TOC) values are notably high in heavy liquid oil-based drilling mud mixtures (TOC $=21.4-63.3 \%$, average $=34.6 \% \pm 8.6$ ) compared to cleaned rock cuttings $(\mathrm{TOC}=0.4-1.5 \%$, average $=0.8 \% \pm 0.3$ ). In addition, drilling mud mixtures contain higher concentrations of unresolved complex mixtures (UCM) in the $n$-alkanes fraction. Therefore, it is difficult to distinguish individual homologues in the $n$-alkanes fraction. The triterpanes also have relatively high UCM contents compared to steranes fractions. However, hydrocarbon homologues can be identified in both the triterpanes and steranes fractions of oil-based drilling mud mixtures. Gas chromatograms indicate that the $n$-alkanes fractions of rock cuttings initially cleaned with solvent still show considerable contamination from drilling fluids. This remaining contamination was removed by an additional cleaning step using the soxhlet extraction technique. The triterpanes fraction in solvent-cleaned rock cuttings does not contain an overprint of heavy liquid oil-based drilling mud contamination. However, solvent-cleaned rock cuttings may still retain contamination signatures at the sterane $\mathrm{C}_{28}-20 \mathrm{R}$ homologue due to coelution. The geochemical overprint of contaminants in the cleaned rock cuttings can be interpreted as infiltration of lower molecular weight compounds into micro-cracks of the cuttings. The distribution of these molecules varies in each hydrocarbon fraction. Therefore, close inspection of contamination effects is required before interpretation of traditional organic geochemical proxies such as source rock characteristics and maturity.
\end{abstract}

Keywords Offshore drilling · Drilling mud · Contamination · Biomarkers · The Mannar Basin

\section{Introduction}

Conventional oil and natural gas resources have played a major role in meeting domestic and industrial energy demand in recent decades. Interest in such resources and global demand for oil and gas have resulted in expansion of present exploration activities into deepwater and Arctic frontier basins (Giles 2004; Gautier et al. 2009). However, hydrocarbon exploration in these deepwater and remote

Amila Sandaruwan Ratnayake

amilageopera@gmail.com

1 Department of Geoscience, Faculty of Science and Engineering, Shimane University, Nishikawatsu-cho 1060, 690-8504 Matsue, Japan

2 Faculty of Science and Technology, Uva Wellassa University, Passara Road, 90000 Badulla, Sri Lanka basins is technically, physically, and economically challenging. Consequently, the limited drilled cores and rock cuttings available are valuable materials for generating information on hydrocarbon exploration. In addition, detailed investigations of drill core and cutting samples are required to make proper assessment of geological and geochemical characteristics (e.g., source rock quality and maturity) to fully evaluate oil and gas resource potential (Jiang et al. 2015; Ratnayake et al. 2018).

As new technology has developed, differing categories of drilling fluids (drilling mud/lubrication) have been used to drill deeper and geometrically more complex wells. Rockcutting samples are thus often contaminated by drilling fluids. These fluids contain a mixture of compounds, including paraffin, olefins, and oil-based esters (Wenger et al. 2004; Toldo Jr and; Zouain 2009). Due to contamination, misleading bulk organic and molecular organic geochemical 
information may thus be acquired from rock cuttings, compared to larger and more intact rock samples from cores (Brocks et al. 1999, 2003; Grosjean and Logan 2007; Reddy et al. 2007; Jarrett et al. 2013). Therefore, it is necessary to develop geochemical methods for evaluating possible sample contamination. Although the use of contamination tracer testing is highly site-specific, it provides an overview of the quality of the rock-cutting samples collected in any particular drilling program.

Molecular-level studies have been widely used to determine the degree of contamination, even in trace-contaminated rock-cutting samples. Gas chromatography combined with mass spectrometry (GC-MS) is one of the most powerful analytical techniques available for characterizing individual molecular compositions of different hydrocarbon fractions (e.g., Moldowan et al. 1985; Brassell et al. 1986; Budzinski et al. 1995; Vékey 2001; Ratnayake et al. 2005; Cortes et al. 2010; Zhang et al. 2012; Jiang et al. 2015). This analytical technique can be successfully applied to distinguish indigenous and contaminant hydrocarbons in the sedimentary organic matter.

In this paper, we investigated the bulk and molecular geochemical characteristics of residual heavy liquid oil-based drilling mud mixtures (oil-based drilling mud) extracted from rock-cutting samples from wells drilled in the Mannar Basin of Sri Lanka. Molecular fractions of $n$-alkanes, triterpanes, and steranes were evaluated qualitatively to compare the geochemical characteristics of the drilling mud used and those of cleaned rock cuttings.

\section{Sampling and methods}

A total of 402 rock-cutting samples were recovered during the 2011 hydrocarbon exploration project conducted by Petroleum Resources Development Secretariat (PRDS) of Sri Lanka using the Chikyu drillship. The rock-cutting samples from the Dorado North and Barracuda exploration wells represent an approximately $4000 \mathrm{~m}$ thickness of Late Cretaceous-to-Miocene calcareous argillaceous to arenaceous sediments in the Mannar Basin (Fig. 1). These samples were highly contaminated by drilling mud and oil. No drilling operation reports or information on the drilling fluid compositions are publically available as yet.

An attempt was made to clean selected rock-cutting samples using chemical methods, as discussed below. In the first step, samples were cleaned manually using $250 \mathrm{ml}$ of dichloromethane: methanol 9:1 v/v solution. To improve the cleaning efficiency, samples were washed manually another two times, using new $50 \mathrm{ml}$ aliquots of dichloromethane:methanol 9:1 solution. The same volume was used for 8 samples, and the cleaned samples were dried at room temperature in a fume cupboard for $24 \mathrm{~h}$. In contrast, the separated residual solutions (i.e., oil-based drilling mud mixtures) were dried at room temperature in a fume cupboard for about 1 week.

The cleaning method was further optimized by sieve separation $(>1 \mathrm{~mm})$ of the solid rock cuttings. The solid rock cuttings (about $25-35 \mathrm{~g}$ ) were then extracted ultrasonically for 30 min using about $75 \mathrm{ml}$ of dichloromethane:methanol $9: 1 \mathrm{v} / \mathrm{v}$ solution. In the last step, samples were again manually washed, using $25 \mathrm{ml}$ of dichloromethane:methanol 9:1 $\mathrm{v} / \mathrm{v}$ solution. The rock-cutting samples were again dried at room temperature in a fume cupboard for $24 \mathrm{~h}$. The cleaned cuttings had a completely oil-free appearance after the soluble-solvent cleaning.

\section{Chemical analyses}

Twenty-five cleaned rock cuttings and their separated dried oil-based drilling muds were treated with $1 \mathrm{M} \mathrm{HCl}$ in silver capsules to remove carbonate carbon, and then dried at $110{ }^{\circ} \mathrm{C}$ for $1 \mathrm{~h}$. The samples were then placed in tin capsules. Total organic carbon (TOC), total nitrogen (TN), and total sulfur (TS) contents were determined using a FISONS EA1180 elemental analyzer. BBOT [2, 5-bis-(5-tert-butyl2-benzoxazol-2-yl)-thiophene] was utilized as a standard for the elemental analyses. All the elemental percentages were expressed on a dry-weight basis.

The dried oil-based drilling mud mixtures were extracted using the soxhlet extraction technique, by refluxing for $72 \mathrm{~h}$ using dichloromethane: methanol 9:1 v/v solution. The lipid extraction of the cleaned rock cuttings was performed in two experimental steps, as follows.

In the first experiment, bitumen was extracted from cleaned rock-cutting samples following exactly the same procedure as above. In the second experiment, the insoluble portions of the first experiment (defined as proto-kerogen, see Vandenbroucke and Largeau 2007), were finely ground. The lipid fraction was again extracted from the proto-kerogen using the soxhlet extraction technique, by refluxing for $72 \mathrm{~h}$ using dichloromethane: methanol 9:1 v/v solution.

Activated copper granules were added in all soxhlet extractions to remove elemental sulfur. The extracts were dried at room temperature, and were separated into compound fractions using UV light on a thin-layer chromatography plate (silica gel $60 \mathrm{PF}_{254}$ containing gypsum), with hexane as a mobile phase.

Hydrocarbon fractions were analyzed using gas chromatography (GC: Shimadzu 2010) coupled with a mass spectrometer (MS: Shimadzu GCMS-QP 2010). The gas chromatograph is equipped with a temperature-programmable injection system, and a fused silica capillary column (DB $5 \mathrm{MS}$ ) of $30 \mathrm{~m}$ length and $0.25 \mathrm{~mm}$ in diameter. Helium was the carrier gas. The oven temperature was programmed from $50{ }^{\circ} \mathrm{C}$ to $300{ }^{\circ} \mathrm{C}\left(\right.$ rate $\left.=8{ }^{\circ} \mathrm{C} / \mathrm{min}\right)$, and retained at $300{ }^{\circ} \mathrm{C}$ 

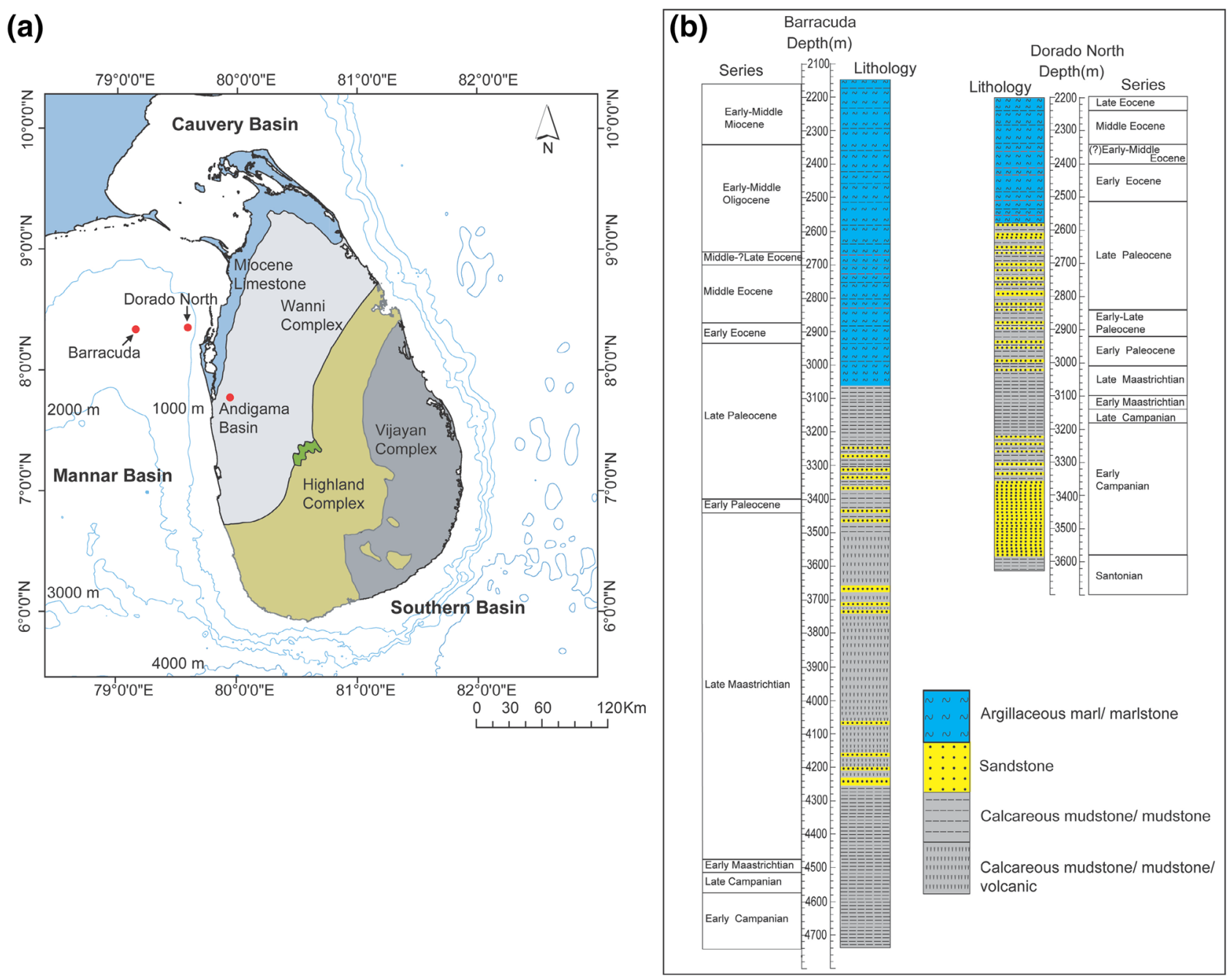

Fig. 1 a Simplified geological map of Sri Lanka showing the locations of hydrocarbon exploration wells in the offshore Mannar Basin and location of the adjacent onshore Andigama Basin, b simplified

for $30 \mathrm{~min}$. The mass spectrometer was operated at an electric energy of $70 \mathrm{eV}$. The mass spectra were recorded over the $\mathrm{m} / \mathrm{z} 50$ to 850 mass fragments. Identification of organic molecular compounds was made using chromatographic retention times, mass spectra, and comparison with standard solutions. The $n \mathrm{C}_{24}$ tetracosane, cholestane, and PAHs mix (Accu Standard Inc. Z-013-17) were used as the external standards.

\section{Results and discussion}

\section{Characterization of dried heavy liquid oil-based drilling mud}

TOC values of all the residual "oil-based drilling mud" samples analyzed were greater than $20 \%$, with a range from lithostratigraphic successions of the Dorado North and Barracuda exploration wells (modified after Ratnayake et al. 2014, 2017a)

21.4 to $63.3 \%$ (average \pm standard deviation $=34.6 \% \pm 8.6$ ) (Table 1). However, the TOC values of the cleaned rock cuttings were all less than $2 \%$, with a range from 0.4 to $1.5 \%$ (average \pm standard deviation $=0.8 \% \pm 0.3$ ) (Table 1$)$. Consequently, removal of contaminants is an essential task for interpretation of source rock properties using the rockcutting samples. Previous work has shown that asphalt additives have TOC contents of approximately $35 \mathrm{wt} \%$ (Wenger et al. 2004). Therefore, contamination from drilling fluids in untreated/unclean rock cuttings can lead to misinterpretation of the quality of source rock compositions.

$\mathrm{C} / \mathrm{N}$ ratios of the oil-based drilling mud range from 25 to 254 (average \pm standard deviation $=104 \pm 63$ ) (Table 1). In contrast, $\mathrm{C} / \mathrm{N}$ ratios of the cleaned rock cuttings are all $<50$, with a range from 7.0 to $45.9 \%$ (average \pm standard deviation $=15.6 \pm 7.2)($ Table 1$)$. Bulk $\mathrm{C} / \mathrm{N}$ ratios can be used as in a wide range of geological samples as a geochemical 
Table 1 Variations of bulk elemental geochemical data in oil-based drilling mud mixtures and cleaned rock cuttings in the Barracuda exploration well (TN: total nitrogen, TOC: total organic carbon, TS: total sulfur, b.d.l: below the detection limit, n.a: not applicable)

\begin{tabular}{|c|c|c|c|c|c|c|c|c|c|c|c|}
\hline \multirow[t]{2}{*}{ Sample No. } & \multirow[t]{2}{*}{ Reference No. } & \multicolumn{5}{|c|}{ Oil-based drilling mud } & \multicolumn{5}{|c|}{ Cleaned rock cuttings } \\
\hline & & $\mathrm{TN}(\%)$ & TOC $(\%)$ & TS (\%) & $\mathrm{C} / \mathrm{N}$ ratio & $\mathrm{C} / \mathrm{S}$ ratio & $\mathrm{TN}(\%)$ & TOC $(\%)$ & TS $(\%)$ & $\mathrm{C} / \mathrm{N}$ ratio & $\mathrm{C} / \mathrm{S}$ ratio \\
\hline 1 & B2790-2860 & 0.39 & 37.70 & 2.35 & 97 & 16 & 0.05 & 0.61 & 0.29 & 10 & 4 \\
\hline 2 & B2860-2940 & 0.26 & 31.93 & 0.91 & 124 & 35 & 0.06 & 0.81 & 0.19 & 13 & 9 \\
\hline 3 & B2950-3020 & 0.51 & 29.19 & 0.07 & 58 & 397 & 0.06 & 0.42 & 0.12 & 8 & 5 \\
\hline 4 & B2940-2950 & 0.67 & 25.48 & 1.46 & 38 & 18 & 0.05 & 0.51 & 0.09 & 10 & 6 \\
\hline 5 & B2780-2790 & 0.14 & 24.64 & b.d.l & 175 & n.a & 0.03 & 1.15 & 0.03 & 46 & 40 \\
\hline 6 & B3020-3100 & 0.33 & 32.82 & 1.44 & 99 & 23 & 0.05 & 0.69 & 0.36 & 14 & 3 \\
\hline 7 & B3100-3110 & 0.25 & 32.55 & 0.98 & 133 & 33 & 0.06 & 0.39 & 0.24 & 7 & 2 \\
\hline 8 & B3110-3180 & 0.27 & 35.84 & 2.00 & 132 & 18 & 0.06 & 0.83 & 0.05 & 14 & 34 \\
\hline 9 & B3180-3260 & 0.18 & 30.54 & b.d.l & 166 & n.a & 0.06 & 1.04 & 0.05 & 17 & 35 \\
\hline 10 & B3260-3270 & 0.11 & 28.62 & b.d.l & 254 & n.a & 0.05 & 0.58 & 0.16 & 11 & 4 \\
\hline 11 & B3270-3340 & 0.49 & 31.10 & b.d.l & 64 & n.a & 0.07 & 1.26 & 0.47 & 17 & 5 \\
\hline 12 & B3340-3420 & 0.38 & 31.56 & 1.00 & 83 & 31 & 0.09 & 1.48 & 0.37 & 17 & 5 \\
\hline 13 & B3420-3450 & 0.38 & 38.73 & 1.39 & 103 & 28 & 0.07 & 1.02 & 0.25 & 15 & 6 \\
\hline 14 & B3420-3430 & 0.15 & 27.88 & 0.73 & 187 & 38 & 0.06 & 0.99 & 0.16 & 16 & 6 \\
\hline 15 & B3500-3570 & 0.23 & 39.73 & 0.90 & 172 & 44 & 0.05 & 0.68 & 0.08 & 14 & 13 \\
\hline 16 & B3650-3730 & 0.15 & 30.49 & 0.47 & 198 & 65 & 0.05 & 1.01 & 0.08 & 20 & 26 \\
\hline 17 & B3730-3810 & 0.74 & 41.25 & 0.78 & 56 & 53 & 0.05 & 0.71 & 0.08 & 14 & 10 \\
\hline 18 & B3810-3890 & 1.05 & 34.53 & b.d.1 & 33 & n.a & 0.06 & 0.94 & 0.21 & 16 & 10 \\
\hline 19 & B3890-3970 & 0.91 & 49.18 & 1.70 & 54 & 29 & 0.05 & 0.61 & 0.18 & 14 & 4 \\
\hline 20 & B3970-4050 & 1.73 & 43.56 & 0.02 & 25 & 2125 & 0.05 & 0.48 & 0.17 & 11 & 3 \\
\hline 21 & B4050-4130 & 1.12 & 32.29 & 0.57 & 29 & 56 & 0.04 & 0.79 & 0.22 & 20 & 4 \\
\hline 22 & B4130-4210 & 0.14 & 21.43 & 0.93 & 152 & 23 & 0.04 & 0.77 & 0.17 & 19 & 5 \\
\hline 23 & B4350-4450 & 0.91 & 36.22 & 0.02 & 40 & 1563 & 0.07 & 1.28 & 0.16 & 20 & 8 \\
\hline 24 & B4600-4670 & 2.01 & 63.32 & 0.07 & 31 & 877 & 0.06 & 0.96 & 0.20 & 16 & 7 \\
\hline 25 & B4670-4741 & 0.38 & 34.79 & 0.39 & 91 & 88 & 0.07 & 0.93 & 0.29 & 13 & 3 \\
\hline
\end{tabular}

fingerprint to identify sources of organic matter (e.g., Meyers and Ishiwatari 1993; Sampei and Matsumoto 2001; Ratnayake et al. 2017b). From a geochemical standpoint, the high $\mathrm{C} / \mathrm{N}$ values of oil-based drilling mud can also thus lead to erroneous interpretation of organic source rock composition in rock cuttings if the contamination is not removed prior to analysis.

The biomarker results are discussed qualitatively in terms of different hydrocarbon fractions (Figs. 2, 3). The characteristics of the $n$-alkanes, triterpanes, and steranes fractions of residual oil-based drilling mud are shown in Fig. 2. Concentrations of unresolved complex mixture (UCM) are abnormally high in the $n$-alkanes fractions (Fig. 2a). The UCM is a fundamental proxy to identify hydrocarbon contamination and biodegradation in geological samples (Jones et al. 1983; Volkman et al. 1992; Grice et al. 2000; Frysinger et al. 2003; Zhang et al. 2012). It is noteworthy that the peak identification is impossible for the $n$-alkanes fractions of these highly condensed samples. Therefore, biomarker analysis of untreated rock cuttings can also be expected to produce highly misleading results. Similarly, the concentrations of
UCM are high in the triterpanes fractions (Fig. 2b) compared to typical non-biodegraded and non-contaminated samples (e.g., Volkman et al. 1992; Grice et al. 2000). This suggests that contamination can also occur in the triterpanes fraction. Although concentrations of UCM are low in the steranes fraction (Fig. 2c), the original composition of organic sources can be seriously altered, as is discussed in the following section.

In this study, no polycyclic aromatic hydrocarbons (PAHs) were detected in the residual oil-based drilling mud mixtures. Wenger et al. (2004) suggested that the absence or low concentrations of aromatic compounds are a distinctive signature of synthetic and/or enhanced mineral oil (EMO)based drilling fluids.

Drilling companies alter the composition of drilling fluids from water-based to oil-based to increase viscosity to enable drilling at deeper levels. However, it is difficult to collect original drilling fluid during the drilling. Furthermore, researcher seldom has the opportunity to assess drilling mud filtrates collected during the drilling operations. In addition, drilling fluids are normally re-used for 

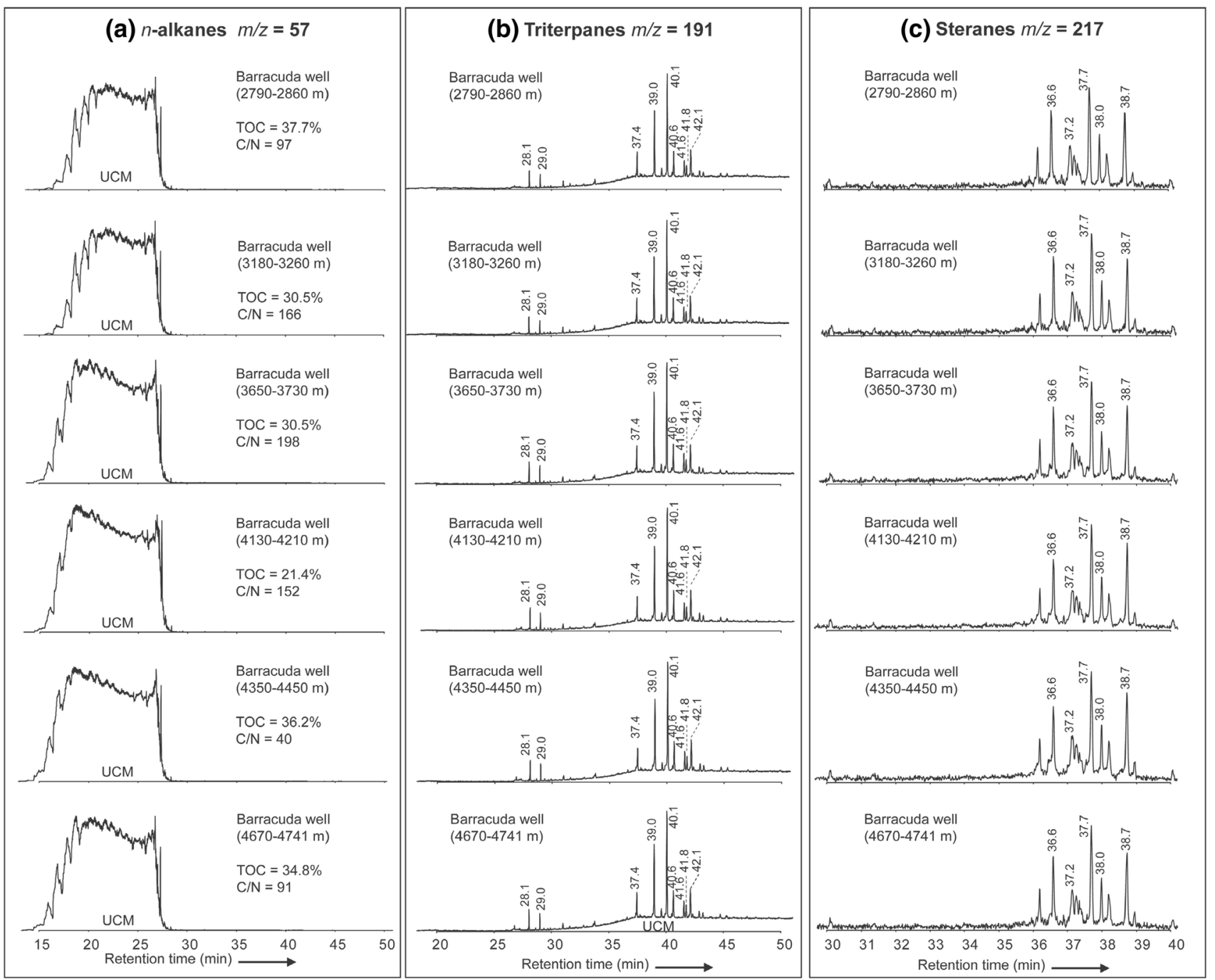

Fig. 2 Mass chromatograms showing distribution of a $n$-alkanes $(m / z=57)$, b triterpanes $(m / z=191)$, and $\mathbf{c}$ steranes $(m / z=217)$ fractions in oilbased drilling mud mixtures

several wells. It is thus important to consider changes of drilling fluid compositions during the drilling (Wenger et al. 2004). In this situation, the main advantage of the method proposed here is to use the oil-based drilling mud mixtures as indicators for determining the degree of contamination, as discussed in the next section.

\section{Contamination effects in the cleaned rock cuttings}

To monitor clues of contaminants, mass chromatographs of the cleaned rock cuttings (i.e., bitumen in the first experiment and kerogen in the second experiment) were compared to (1) oily drilling residues and (2) non-contaminated outcrop samples from the adjacent onshore sedimentary basin (Fig. 3).

\section{Bitumen fraction}

In the first experiment, the $n$-alkanes fractions of extracted bitumen show greater amounts of UCM after the chemical cleaning process (Fig. 3a). This suggests the occurrence of non-indigenous hydrocarbons in the $n$-alkanes fractions of the extracted bitumen (Fig. 3a). According to the literature, it is difficult to remove compounds such as the polyalkylated glycols that are commonly used for preventing gas-hydrate formation in drilling mud, by depressing freezing points (Wenger et al. 2004). In contrast, based on kinetic effects, lower molecular weight hydrocarbons can move faster and further under lower absorption energy than heavier homologues (Jarrett et al. 2013). Therefore, lower molecular weight $n$-alkanes can infiltrate the interiors of rock cuttings at millimeter to centimeter scale 

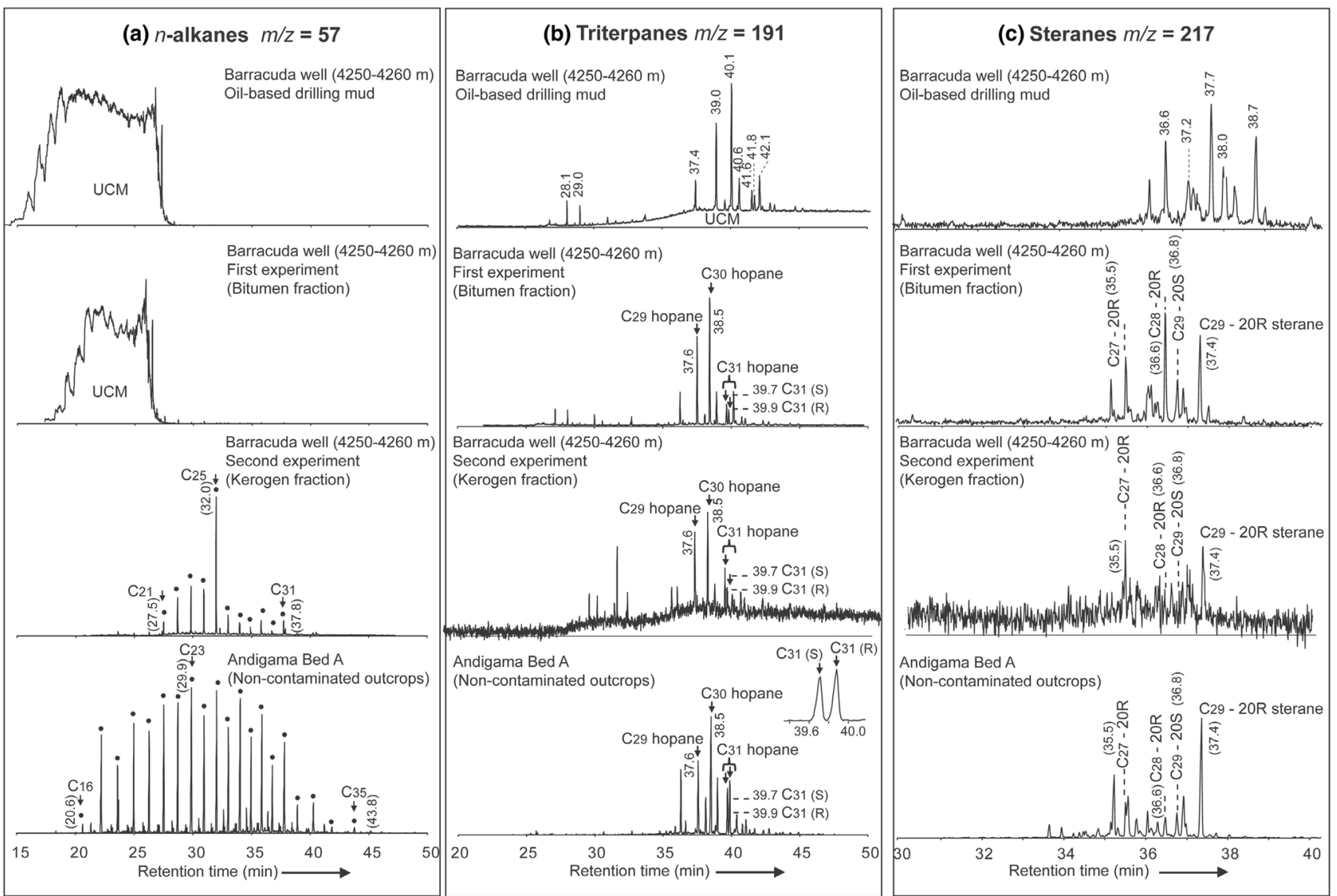

Fig. 3 Comparison of representative a $n$-alkanes, b triterpanes, and c steranes fractions in oil-based drilling mud, cleaned rock cuttings (first experiment), cleaned rock cuttings (second experiment) from the Barracuda exploration well, and uncontaminated Jurassic sedimentary rocks from the onshore Andigama Basin (after Ratnayake and Sampei 2015a) by passage through micro-fractures, particularly along bedding/cutting planes. Similarly, the previous investigations suggested enhancement of lower molecular weight $n$-alkanes/ $n$-alkanes in contaminated samples (Brocks et al. 2003; Shang et al. 2006; Reddy et al. 2007). According to Wenger et al. (2004), the cheaper and commonly available oil-based drilling fluids contain unimodal $n$-alkanes distributions with maxima at $n$ - $\mathrm{C}_{16}$.

The triterpanes (Fig. 3b) and steranes (Fig. 3c) fractions of oil-based drilling mud show slightly higher retention time compared to regular molecular compounds. The deviated retention times in drilling fluids can also be used as a proxy to recognize the degree of contamination in cleaned rock cuttings (Brocks et al. 2003; Shang et al. 2006; Reddy et al. 2007). The mixing of residual heavier components (e.g., asphalt/gilsonite, barium sulfate, and artificial additives) can cause higher retention times after each regular homologue, as shown by the triterpanes (Fig. 3b) and steranes (Fig. 3c) fractions in oil-based drilling mud. Consequently, the reduction of retention times in cleaned rock cuttings can generally indicate cleansing of contaminants in the triterpanes and steranes fractions.

The contamination effect is negligible for the triterpanes fractions in cleaned rock cuttings, as discussed above. In addition, oil-based drilling mud could not elute in the same analytical window of the main $\mathrm{C}_{29}, \mathrm{C}_{30}$ and $\mathrm{C}_{31}$ hopane peaks (Fig. 3b). Specifically, the $22 \mathrm{~S} /(22 \mathrm{~S}+22 \mathrm{R})$ ratio of the $\mathrm{C}_{31} 17 \alpha$ hopanes can be recognized as a commonly used biomarker proxy indicating thermal maturity (Farrimond et al. 1998; Pan et al. 2008; Ratnayake and Sampei 2015a). In this study, analytical results indicate that the maturityindicating biomarker proxy was not affected in the cleaned rock-cutting samples (Fig. 3b). However, analytical problems remain in the steranes fraction due to coelution. In particular, the $\mathrm{C}_{28}$-20R sterane peak of indigenous hydrocarbon can partially overlap remaining drilling mud and oil peaks within a single peak (Fig. 3c). In addition, it is difficult to isolate the proportion of indigenous and artificial components in the $\mathrm{C}_{28}$-20R sterane homologue. Consequently, results for sterane biomarkers can create misleading quantitative estimates 
of biological precursors in the reference $\mathrm{C}_{27}-\mathrm{C}_{28}-\mathrm{C}_{29}$ sterane ternary diagram (e.g., Huang and Meinschein 1979). However, in the solvent cleaned cutting samples, this effect does not influence determination of thermal maturity using the ratio of $\mathrm{C}_{29}$ sterane $20 \mathrm{~S} /(20 \mathrm{~S}+20 \mathrm{R})$ (Ratnayake and Sampei 2015b).

\section{Kerogen fraction}

In the second experiment, we extracted the less soluble fraction to enhance cleaning efficiency. The extracted saturated fraction indicates that $n$-alkanes composition ranged from $n \mathrm{C}_{17}$ to $n \mathrm{C}_{33}$, with middle chain length $n$-alkanes predominant (Fig. 3a). In addition, the relative distribution of lower molecular weight $n$-alkanes $\left(<n \mathrm{C}_{21}\right)$ content is remarkably low, possibly due to preferential release of lower molecular weight compounds during the early stages of solvent cleaning/extractions and/or original organic matter composition. The signal intensities of UCM are also low for the $n$-alkanes faction (Fig. 3a). These features suggest almost complete cleaning of the rock cuttings after the second experiment. Hopanes and steranes concentrations are very low compared to the first experiment, and steranes concentrations are close to the detection limits in some samples (Fig. 3b, c).

\section{Conclusions}

The proposed cleaning and analytical methods can be applied to millimeter- to centimeter-scale rock cuttings. However, some contamination can still remain in the interiors of rock cuttings after the solvent-soluble cleaning. Therefore, in uncleaned rock cuttings, the presence of residual oil-based drilling mud can significantly influence bulk organic geochemical signatures such as organic richness and source composition. The evaluation of biomarkers in drilling fluid also indicates higher concentrations of UCM in the $n$-alkanes and triterpanes fractions due to contamination. The mass spectra of drilling mud mixtures indicate structurally different organic compounds in both the triterpanes and steranes fractions, based on retention times.

It is possible to remove both exterior and interior contamination of hydrocarbons in the triterpanes fraction using solvent-soluble cleaning methods, as discussed in this study. However, it is important to note that trace contaminant and indigenous hydrocarbons can remain in the steranes fraction due to coelution at the $\mathrm{C}_{28}-20 \mathrm{R}$ sterane peak. The $n$-alkanes fractions required the additional step of lipid extraction to fully remove contaminated hydrocarbons. Consequently, compound-specific variation can be observed in different hydrocarbon fractions during chemical cleaning, due to uneven removal of structurally differing compounds.
Finally, this study demonstrated that it is essential to (1) fully remove residual oil-based drilling mud from rock cuttings, (2) identify the geochemical properties of oil-based drilling mud, and (3) estimate any remaining contamination effects in cleaned rock cuttings. If these conditions are met, the cleaned rock cuttings can be used for straightforward interpretation of maturity, organic matter composition and paleoenvironmental characteristics in deepwater petroleum source rocks such as those encountered in the Mannar Basin.

Acknowledgements This work was supported by a MEXT Scholarship from the Japanese Ministry of Education and Culture. We thank Director General Saliya Wickramasuriya and Petroleum Geologist C.W. Kularathne of the Petroleum Resources Development Secretariat (PRDS) of Sri Lanka for kindly providing the rock cuttings examined in this study. We acknowledge Dr. Barry P. Roser (Shimane University, Japan) for valuable comments and editorial suggestions, and thank Editor-in-Chief Prof. Turgay Ertekin and two anonymous reviewers for their very constructive and helpful comments on an earlier draft of this manuscript.

Open Access This article is distributed under the terms of the Creative Commons Attribution 4.0 International License (http://creativeco mmons.org/licenses/by/4.0/), which permits unrestricted use, distribution, and reproduction in any medium, provided you give appropriate credit to the original author(s) and the source, provide a link to the Creative Commons license, and indicate if changes were made.

\section{References}

Brassell SC, Eglinton G, Mo FJ (1986) Biological marker compounds as indicators of the depositional history of the Maoming oil shale. Org Geochem 10:927-941

Brocks JJ, Logan GA, Buick R, Summons RE (1999) Archean molecular fossils and the early rise of eukaryotes. Science 285:1033-1036

Brocks JJ, Buick R, Logan GA, Summons RE (2003) Composition and syngeneity of molecular fossils from the 2.78 to 2.45 billion-yearold Mount Bruce Supergroup, Pilbara Craton, Western Australia. Geochim Cosmochim Acta 67:4289-4319

Budzinski H, Garrigues PH, Connan J, Devillers J, Domine D, Radke M, Oudin JL (1995) Alkylated phenanthrene distributions as maturity and origin indicators in crude oils and rock extracts. Geochim Cosmochim Acta 59:2043-2056

Cortes JE, Rincon JM, Jaramillo JM, Philp RP, Allen J (2010) Biomarkers and compound-specific stable carbon isotope of $n$-alkanes in crude oils from Eastern Llanos Basin, Colombia. J South Am Earth Sci 29:198-213

Farrimond P, Taylor A, Telnaes N (1998) Biomarker maturity parameters: the role of generation and thermal degradation. Org Geochem 29:1181-1197

Frysinger GS, Gaines RB, Xu L, Reddy CM (2003) Resolving the unresolved complex mixture in petroleum-contaminated sediments. Environ Sci Technol 37:1653-1662

Gautier DL, Bird KJ, Charpentier RR, Grantz A, Houseknecht DW, Klett TR, Moore TE, Pitman JK, Schenk CJ, Schuenemeyer JH, Sørensen K, Tennysoon ME, Valin ZC, Wandrey CJ (2009) Assessment of undiscovered oil and gas in the Arctic. Science 324:1175-1179

Giles J (2004) Every last drop. Nature 429:694-695 
Grice K, Alexander R, Kagi RI (2000) Diamondoid hydrocarbon ratios as indicator of biodegradation in Australian crude oils. Org Geochem 31:67-73

Grosjean E, Logan GA (2007) Incorporation of organic contaminations into geochemical samples and an assessment of potential sources: Examples from Geoscience Australia marine survey S282. Org Geochem 38:853-869

Huang WY, Meinschein WG (1979) Sterols as ecological indicators. Geochim Cosmochim Acta 43:739-745

Jarrett AJM, Schinteie R, Hope JM, Brocks JJ (2013) Micro-ablation, a new technique to remove drilling fluids and other contaminants from fragmented and fissile rock material. Org Geochem 61:57-65

Jiang H, Pang X, Shi H, Yu Q, Cao Z, Yu R, Chen D, Long Z, Jiang F (2015) Source rock characteristics and hydrocarbon expulsion potential of the Middle Eocene Wenchang formation in the Huizhou depression, Pearl River Mouth basin, south China Sea. Mar Petrol Geol 67:635-652

Jones DM, Douglas AG, Parkes RJ, Taylor J, Giger W, Schaffner C (1983) The recognition of biodegraded petroleum-derived aromatic hydrocarbons in recent marine sediments. Marine Poll Bull 14:103-108

Meyers PA, Ishiwatari R (1993) Lacustrine organic geochemistry-an overview of indicators of organic matter sources and diagenesis in lake sediments. Org Geochem 20:867-900

Moldowan JM, Seifert WK, Gallegos EJ (1985) Relationship between petroleum composition and depositional environment of petroleum source rocks. ґAAPG Bull 69:1255-1268

Pan C, Peng D, Zhang M, Yu L, Sheng G, Fu J (2008) Distribution and isomerization of $\mathrm{C}_{31}-\mathrm{C}_{35}$ homohopanes and $\mathrm{C}_{29}$ steranes in Oligocene saline lacustrine sediments from Qaidam Basin, Northwest China. Org Geochem 39:646-657

Ratnayake AS, Sampei Y (2015a) Characterization of organic matter and depositional environment of the Jurassic small sedimentary basins exposed in the northwest onshore area of Sri Lanka. Res Org Geochem 31:15-28

Ratnayake AS, Sampei Y (2015b) Preliminary prediction of the geothermal activities in the frontier Mannar Basin, Sri Lanka. J Geol Soc Sri Lanka 17:19-29

Ratnayake NP, Suzuki N, Matsubara M (2005) Sources of long chain fatty acids in deep sea sediments from the Bering Sea and the North Pacific Ocean. Org Geochem 36:531-541

Ratnayake AS, Sampei Y, Kularathne CW (2014) Stratigraphic responses to major depositional events from the Late Cretaceous to Miocene in the Mannar Basin, Sri Lanka. J Geol Soc Sri Lanka 16:5-18
Ratnayake AS, Sampei Y, Kularathne CW (2017a) Current status of hydrocarbon exploration in Sri Lanka. Int J Oil Gas Coal Technol 16:377-389

Ratnayake AS, Sampei Y, Ratnayake NP, Roser BP (2017b) Middle to late Holocene environmental changes in the depositional system of the tropical brackish Bolgoda Lake, coastal southwest Sri Lanka. Palaeogeogr Palaeoclimatol Palaeoecol 465:122-137

Ratnayake AS, Kularathne CW, Sampei Y (2018) Assessment of hydrocarbon generation potential and thermal maturity of the offshore Mannar Basin, Sri Lanka. J Pet Explor Prod Techno 8:641-654

Reddy CM, Nelson RK, Sylva SP, Xu L, Peacock EA, Raghuraman B, Mullins OC (2007) Identification and quantification of alkenebased drilling fluids in crude oils by comprehensive two-dimensional gas chromatography with flame ionization detection. J Chromatogr A 1148:100-107

Sampei Y, Matsumoto E (2001) C/N ratios in a sediment core from Nakaumi Lagoon. southwest, Japan. Geochem J 35:189-205

Shang H, Snape CE, Kingman SW, Robinson JP (2006) Microwave treatment of oil-contaminated North Sea drill cuttings in a high power multimode cavity. Sep Purif Technol 49:84-90

Toldo EE Jr, Zouain RNA (2009) Environmental monitoring of offshore drilling for petroleum exploration (MAPEM): A brief overview. Deep Sea Res II 56:1-3

Vandenbroucke M, Largeau C (2007) Kerogen origin, evolution and structure. Org Geochem 38:719-833

Vékey K (2001) Mass spectrometry and mass-selective detection in chromatography. J Chromatogr A 921:227-236

Volkman JK, Holdsworth DG, Neill GP, Bavor HJ Jr (1992) Identification of natural, anthropogenic and petroleum hydrocarbons in aquatic sediments. Sci Total Environ 112:203-219

Wenger LM, Davis CL, Evensen JM, Gormly JR, Mankiewicz PJ (2004) Impact of modern deepwater drilling and testing fluids on geochemical evaluations. Org Geochem 35:1527-1536

Zhang Z, Greenwood P, Zhang Q, Rao D, Shi W (2012) Laser ablation GC-MS analysis of oil-bearing fluid inclusions in petroleum reservoir rocks. Org Geochem 43:20-25

Publisher's Note Springer Nature remains neutral with regard to jurisdictional claims in published maps and institutional affiliations. 